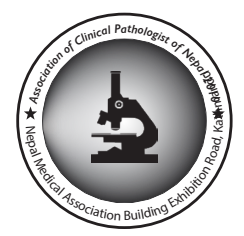

\title{
Correlation of ultrasonography guided fine needle aspiration cytology of thyroid nodules with histopathology
}

\author{
Banstola Laxman ${ }^{1}$ \\ ${ }^{I}$ Consultant Pathologist, Department of Pathology, Western Regional Hospital, Pokhara, Nepal
}

\author{
Keywords: \\ Bethesda system; \\ Fine needle aspiration \\ cytology; \\ Neoplasia; \\ Thyroid;
}

\begin{abstract}
Background: This study aims to establish correlation of ultrasonography guided fine needle aspiration cytology (USG-FNAC) of thyroid nodules with histology. USG-FNAC was carried out in fifty cases of thyroid nodules and the result of USG-FNAC was compared with histopathology.
\end{abstract}

Materials and Methods: The study was performed in the Department of Pathology, National Academy of Medical Sciences, Bir Hospital over a period of one year. Fine needle aspiration of solid area of thyroid nodule was done in each case with USG guidance. FNAC results were classified according to Bethesda system of reporting. Finally, comparison was done between cytological and histological findings.

Results: The age of patients that underwent thyroidectomy ranged from 16 - 70 years. Maximum number of cases fell in age group 31-40 years. Female patients outnumbered male patients by a ratio of 9: 1.On cytological study, $70 \%$ cases were diagnosed as benign, $28 \%$ as malignant and $2 \%$ as inadequate for evaluation. On histopathology, $70 \%$ cases of diagnosed cases were benign lesions. Nodular hyperplasia and colloid goiter were kept under the term 'follicular nodule'. Follicular nodule was the most commonly diagnosed thyroid lesion. Fifteen cases of nodular hyperplasia and fourteen cases of colloid goiter were detected. Total number of malignant cases diagnosed was 15 , out of which papillary carcinoma was the commonest (66.67\%). We found two cases of medullary thyroid carcinoma. Conclusion: Sensitivity and specificity of USG-FNAC was $93.33 \%$ and $100 \%$, respectively. The study showed significant correlation between FNAC (USG-guided in this study) and histopathology.

\section{Correspondence:}

Dr. Laxman Banstola, MBBS, MD

Consultant Pathologist

Department of pathology, Western Regional Hospital, Pokhara, Nepal

Email:lbanstola@hotmail.com

ORCID ID: 0000-0002-2616-6549

Reveived : June 27 2017 ; Accepted : September $5^{\text {th }}$ 2017; Published : March $21^{\text {st }} 2017$

Citation: Banstola L. Correlation of ultrasonography guided fine needle aspiration cytology of thyroid nodules with histopathology. J Pathol Nep 2018;8: 1271-5. Doi: 10.3126/jpn.v8i1.19450

Copyright: This is an open-access article distributed under the terms of the Creative Commons Attribution 4.0 International License, which permits unrestricted use, distribution, and reproduction in any medium, provided the original author and source are credited.

\section{INTRODUCTION}

The prevalence of thyroid nodules is reported to be 4-7 percent. Of these, one in twenty nine turn out to be malignancy.1Only about $20 \%$ of patients undergoing thyroid surgery for suspicion of malignancy after fine needle aspiration cytology actually show malignancy in histopathology. Prior to advent of FNAC, about $50 \%$ of the patients with thyroid nodules were operated, with malignancy found in up to 0.55 to 25 percent. Moreover $20-48 \%$ of patients with single palpable thyroid nodule are found to have additional nodules when investigated by ultrasonography. ${ }^{2}$ Of these, selected patients can be advised for surgery on the basis of FNAC report and rest can be 
Table1. Benign and Malignant diagnosis in FNAC and HPE

\begin{tabular}{lll}
\hline \multicolumn{1}{c}{ Microscopic lesion } & Diagnosis & Frequency (\%) \\
\hline \multirow{2}{*}{$\begin{array}{l}\text { Fine Needle Aspiration } \\
\text { Cytology }\end{array}$} & Benign & $34(68)$ \\
& $\begin{array}{l}\text { Malignant } \\
\text { Inadequate for } \\
\text { evaluation }\end{array}$ & $14(28)$ \\
& Total & $\mathbf{5 0}(\mathbf{1 0 0})$ \\
$\begin{array}{l}\text { Histopathological } \\
\text { Examination }\end{array}$ & Benign & $35(70)$ \\
& Malignant & $15(30)$ \\
& Total & $\mathbf{5 0}(\mathbf{1 0 0})$
\end{tabular}

followed up.

FNAC is simple, minimally invasive, and cost effective. It is considered as the gold standard investigation in diagnosis of thyroid nodules. It provides highly accurate cytological information from which a definitive management plan can be formulated. FNAC has high sensitivity and specificity approaching to $96 \%$. Several studies have reported that USGFNAC not only reduces the inadequacy rate but also helps to accurately select the patients who actually need surgery; hence, avoiding unnecessary diagnostic thyroidectomies. ${ }^{3}$ However, even FNAC has limitations because of low yield of cells and inability to distinguish follicular adenoma from follicular carcinoma.

In this study, fifty patients with thyroid nodules were enrolled. USG-FNAC diagnosis was made and histopathology examination was done following thyroid surgery from ENT-HNS department. Correlation between cytology and histology was done to determine the role of FNAC in thyroid nodules.

\section{MATERIALS AND METHODS}

Patients underwent an ultrasound-guided fine-needle aspiration of the thyroid nodules. Prior to conduction of this study, permission was obtained from institutional review committee. Patients of all ages, both male and female who underwent surgery for thyroid swelling with subsequent histopathological study of excised tissue, were included in this study.

Fine needle aspiration of solid area of thyroid nodule was done in each case with USG guidance. Aspiration technique with 23 Gauge needle connecting to a $10-\mathrm{ml}$ syringe was used. Multiple needle passes, usually 3-4 times were made within the lesion at varying angles and depths and with constant negative pressure. Before final withdrawal, the negative pressure was released prior to the needle emerging out from the skin. The cytological material was transferred on to glass slides. The aspirated material was then smeared on 2-4 slides, fixed in 95\% ethanol and stained by Papanicoloau stain. The air dried slides were stained with Giemsa stain. The stained slides were seen under light microscope and the FNAC results were classified according to Bethesda system of reporting. The biopsy specimen which was well fixed in $10 \%$ formalin solution, was grossed, processed through automatic tissue processor and stained with H\&E stain. Data were collected in Microsoft Excel and were analyzed in SPSS vs. 17.

\section{RESULTS}

The age of patients ranged from $16-70$ years. Female to male ratio was 9:1. FNAC diagnosis was made based on Bethesda system of reporting. According to Bethesda system of reporting, nodular hyperplasia, adenomatoid nodule, colloid nodule and colloid goiter were kept under the term 'Benign follicular nodule'. Twenty eight cases $(56 \%)$ were of follicular nodule, eight cases $(16 \%)$ were of papillary carcinoma (fig.1), four cases (8\%) were of suspicious of follicular neoplasm, three cases $(6 \%)$ were of suspicious of malignancy, two cases $(4 \%)$ were of medullary carcinoma (fig.2), two cases (4\%) were of follicular lesion of undetermined significance and one case $(2 \%)$ was of Hashimoto thyroiditis (fig.3). In two cases (4 $\%$ ) appropriate cytological diagnosis could not be given due to lack of adequate cellular components. These cases were labeled 'inadequate for evaluation'.

Out of fifty cases, fifteen cases $(30 \%)$ were of nodular hyperplasia, fourteen cases (28\%) were colloid goiter, ten cases $(20 \%)$ were papillary thyroid carcinoma, five cases $(10 \%)$ of follicular adenoma, two cases $(4 \%)$ of medullary carcinoma, two cases (4\%) of poorly differentiated carcinoma, one case $(2 \%)$ of well differentiated tumour of uncertain malignant potential and one case $(2 \%)$ of Hashimoto thyroiditis. On Fine Needle Aspiration Cytology, benign cases were $68 \%$, malignant cases were $28 \%$ and $4 \%$ cases were Inadequate for evaluation. On HPE examination, $70 \%$ cases were categorized benign and $30 \%$ were malignant (Table 1). Sensitivity, specificity, PPV, NPV came $93.33 \%, 100 \%, 100 \%$ and $97.05 \%$ respectively. Total number of malignant cases diagnosed was 15 , out of which papillary carcinoma was the commonest $(66.67 \%)$ as shown in (Table 2).

\section{DISCUSSION}

FNAC is the first line of investigation on thyroid swellings. It provides diagnosis with reasonable accuracy. Management plan can be based on the FNAC diagnosis. If the swelling is diagnosed as benign, patient can be advised for wait and watch policy. But malignant nodules need to be intervened outright with surgery. FNAC has proved to be a great tool to the clinicians as regards decision making in treatment.

FNAC is a reliable test and correct diagnosis can be achieved. But there are some shortcomings as well. Occasionally, only fluid is aspirated and no cells are appreciated in the slide, in which cases a diagnosis cannot be made. Such cases have to be labeled 'inadequate for evaluation'. Repeat test has to 


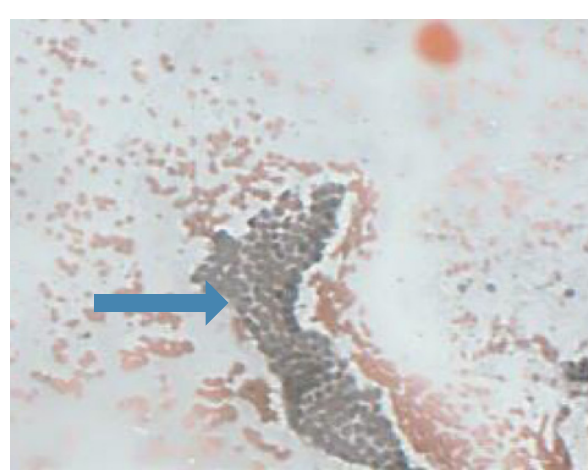

Figure 1: Aspiration smear of Papillary thyroid carcinoma: Papillary architecture (arrow) with hard edges. (Giemsa stain, X100)

Table 2.Types of malignancy diagnosed on histopathology

\begin{tabular}{lc}
\hline \multicolumn{1}{c}{ HPE Diagnosis } & Number of cases (\%) \\
\hline Papillary carcinoma & $10(66.67)$ \\
Medullary carcinoma & $2(13.33)$ \\
Poorly differentiated carcinoma & $2(13.33)$ \\
$\begin{array}{l}\text { Well differentiated carcinoma of } \\
\text { undetermined significance }\end{array}$ & $1(6.67)$ \\
\hline Total cases of malignancy & $\mathbf{1 5 ( 1 0 0 )}$ \\
\hline
\end{tabular}

be requested in such circumstances. Follicular carcinoma is another arena where FNAC diagnosis falls short.

Since the introduction of USG guided FNAC (USGFNAC), several studies have reported that USG-FNAC not only reduces the inadequacy rate but also helps to accurately select the patients for surgery. ${ }^{3}$ Unnecessary thyroidectomies can be avoided with such line of investigation. It does this by selection of the biopsy site. Cystic areas and coarse calcification are also avoided. Its role has been found useful in detecting micro-carcinomas, cystic carcinomas, malignancy associated with benign conditions for example Hashimoto's thyroiditis. Rates of nondiagnostic FNAC results can be reduced with USGFNAC. However, nondiagnostic samplings still do occur with USG-FNAC too.

The age range and female: male ratio found from this study correlates with similar other studies. The peak incidence of thyroid swelling was observed in 21-30 years of age..$^{4-7}$

In the present study, as per Bethesda system of reporting, diagnosis of follicular nodule encompassed colloid nodule, colloid goiter and adenomatoid nodule. Similarly, neoplastic group comprised of diagnosis of suspicious for malignancy, suspicious for follicular neoplasm, papillary carcinoma, medullary carcinoma and follicular lesion of undetermined significance. Two cases could not be diagnosed because of lack of cellular components. In 'Role of fine needle aspiration cytology in diagnosis and management of thyroid lesions' by Uma H, Sukant G, Harsh M, Nitin N, it is elaborated that among 434 cases, twenty two cases were

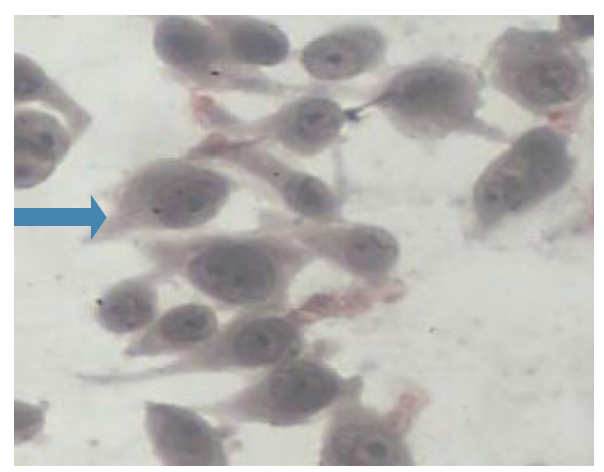

Figure 2: Aspiration smear of Medullary thyroid carcinoma: Dispersed plasmacytoid cells(arrow). (Pap smear; X40)

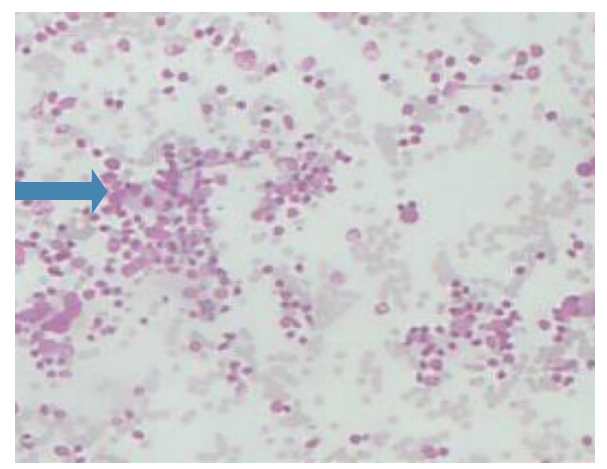

Figure 3: Aspiration smear of Hashimoto thyroiditis: Plenty of lymphocytic cells (arrow) admixed with follicular epithelial cells.

(Giemsa stain; X100)

diagnosed as inadequate because of lack of cellularity. Most common lesion was colloid goiter, followed by thyroiditis8. Others were adenomatous goiter and thyroglossal cysts among non-neoplastic lesions. Neoplastic group in FNAC comprised of Hurthle cell neoplasm, papillary carcinoma, medullary carcinoma, anaplastic carcinoma and metastatic carcinoma.

Most of our cases regarding follicular nodule showed moderate cellularity comprising of sheets and clusters of cohesive, evenly spaced, uniform follicular epithelial cells. The background showed abundant colloid and colloid laden macrophages along with red blood cells. Uma H, Sukant G, Harsh M, Nitin N have mentioned the cytologic features of colloid goiter as: follicular epithelial cells, cyst macrophages (59.4\%), fire flares (6.34\%), lymphocytic infiltrate (2.38\%) and Hurthle cell changes $(1.58 \%){ }^{8}$ The smears diagnosed as papillary cell carcinoma showed increased cellularity of tumor cells arranged in monolayered sheets, papillae and clusters. The individual tumor cells were moderate in size, most of them cuboidal in shape with scant cytoplasm and nuclei with "powdery" chromatin. In most of the cases nuclei displayed grooves and pseudo inclusions in few cases. Some of these nuclei exhibited small nucleolus as well. The thick and irregular nuclear border along with nuclear crowding and overlapping were also noted in the smears. However, psammoma bodies and multinucleated giant cells 
were not seen in any of these smears. Papillary carcinoma cases were diagnosed by Uma H, Sukant G, Harsh M, Nitin $\mathrm{N}$ based on features of papillary clusters of cells with pale nuclei, intranuclear cytoplasmic invaginations, irregular nuclear outlines, and nuclear grooves. ${ }^{8}$ Hurthle cell changes were noted in five cases and psammoma bodies were seen in three cases. Ali N, Alaa J H, Rasha K A included following criteria for cytological diagnosis of papillary thyroid carcinoma: hypercellularity, papillary configuration, large hyperchromatic nuclei and opened chromatin. ${ }^{9}$ Basharat R, Bukhari MH, Saeed S, Hamid T have stressed that slides of papillary thyroid carcinoma showed hypochromasia/pallor, nuclear grooves, intranuclear cytoplasmic inclusions, ovoid nucleus, and micronucleus. ${ }^{10}$

There were cases of smears suspicious for follicular neoplasm. The smears showed increased cellularity of follicular epithelial cells arranged in clusters, microfollicles and sheets. Cells were moderately pleomorphic with hyperchromatic nuclei and some even had prominent nucleoli. It also showed scant colloid material in the background. Basharat R, Bukhari MH, Saeed S, Hamid $\mathrm{T}$ have described the presence of marked cellularity, discohesion and microfollicles in cases of follicular neoplasm. Marked nuclear atypia, mitosis and necrosis were uncommon in their study. ${ }^{10}$ Follicular neoplasm was diagnosed by Uma H, Sukant G, Harsh M, Nitin N when smears showed follicular epithelial cells distributed in follicular structures or sheets with a small quantity of colloid. If oxyphilic cells dominated, diagnosis of Hurthle cell neoplasm was made. ${ }^{8}$

The diagnosis of medullary carcinoma was made in two cases. The aspiration smears showed highly cellular areas of cells arranged predominantly dispersed singly. The individual cells were moderately pleomorphic consisting predominantly of plasmacytoid cells. Amyloid like material was seen. Uma $\mathrm{H}$, Sukant G, Harsh M, Nitin $\mathrm{N}^{8}$ have discussed that there were three cases of medullary carcinoma, which showed the presence of cuboidal to rounded cells with oval, eccentric, pleomorphic nuclei with abundant cytoplasm. Congo red-positive material was seen in one case.

In the present study, sensitivity and specificity of FNAC (USG-FNAC) were calculated to be $93.33 \%$ and 100 $\%$ respectively. Similarly, positive predictive value and negative predictive value were $100 \%$ and $97.05 \%$, while diagnostic accuracy was $97.91 \%$. These results are comparable to other published studies in literature. ${ }^{11-13}$ Chandanwale S, Singh N, Kumar H, Pradhan P, Gore C, Rajpal M derived sensitivity, specificity, diagnostic accuracy, PPV and NPV of FNAC as $90 \%, 100 \%, 87.5 \%, 100 \%$ and $90 \%$ respectively. 14Meraj FA, Fatemah SR, Perviz FA found sensitivity, specificity, positive predictive value, negative predictive value and diagnostic accuracy to be 89.6 $\%, 100 \%, 100 \%, 65 \%$ and $91.25 \%$ respectively. They have emphasized that FNAC is an acceptable and affordable method for diagnosis of thyroid nodules. They have stressed that FNAC and ultrasound studies, significantly reduces unnecessary surgery. ${ }^{15}$ Prakash JM, Jyothi BL, Hiremath SS, Kishanprasad HL, Nagesh T S, Joshua DJM have concluded that FNAC is a good diagnostic tool for solitary thyroid nodules, while ultrasound guided FNAC would have been better option for increasing accuracy of the diagnosis. ${ }^{16}$ Gupta M, Gupta S, Gupta BV have emphasized that FNAC diagnosis of malignancy is highly significant and such patients should be subjected to surgery. ${ }^{17}$ They have also discussed that benign FNAC diagnosis should be viewed with caution as false negative results do occur and these patients should be followed up. Clinical suspicion of malignancy even in the presence of benign FNAC requires surgery. Basharat R, Bukhari MH, Saeed S, Hamid T have concluded that FNAC should be advised for every patient with thyroid nodule for exclusion of malignancy. According to them, as FNAC is a sensitive, specific, an inexpensive, and accurate procedure, it should be adopted as an initial investigation of thyroid diseases in all tertiary hospitals. ${ }^{10}$

\section{CONCLUSION}

Sensitivity and specificity of USG-FNAC was $93.33 \%$ and $100 \%$, respectively. The study showed significant correlation between FNAC (USG-guided in this study) and histopathology. Because of high sensitivity and specificity, USG guided FNAC should be adopted as an initial investigation modalities for thyroid disease.

\section{Conflict of interest: None}

\section{REFERENCES}

1. Mathew J. Burden of thyroid diseases in India. Need for Aggressive Diagnosis. Cited [2007,April] Crossref

2. Nilakantan A, Venkatesh MD, Raghavan D, Datta R, Sharma V. Ultrasonography: its role in nodular thyroid disease. Indian $\mathrm{J}$ Otolaryngol Head Neck Surg. 2007;59:332-5. Crossref

3. Bellantone R, Lombardi CP, Raffaelli M, et al. Management of cystic or predominantly cystic thyroid nodules: the role of ultrasound-guided fine-needle aspiration biopsy. Thyroid. 2004;14:43-7. Crossref

4. Nepali R, Banita V, Thakur G. Comparative study of FNAC and histopathology in diagnosis of thyroid swellings. Journal of Head and Neck Surgery 2011 Jul;5:2.

5. Khan ZT, Baloch AT, Ahmed Z, Hafeez A, Tasleem Q. The yield of FNAC in thyroid nodule. Medical Channel. 2012;19:66-9.

6. Mubasher I, Jamil H, Sohail M, Sheema H. Fine Needle aspiration cytology (FNAC) in the management of thyroid pathology. Journal Of Pakistan Medical Association. 1999; 49:133-5.

7. Komal SL, Rakesh AH, Santosh GG, Umashankar S. Diagnostic accuracy of fine needle aspiration cytology in thyroid lesions-a hospital based study. 2013;10:68-71.

8. Uma H, Sukant G, Harsh M, Nitin N. Role of fine needle aspiration cytology in diagnosis and management of thyroid lesions: a study on 434 patients. J Cytol 2008;25:13-7. $\underline{\text { Crossref }}$

9. Ali N, Alaa J H, Rasha K A. The Role of FNAC in diagnosis of papillary carcinoma of thyroid. IOSR-Journal of Dental and Medical Sciences. 2013;6:7-13. Crossref 
10. Basharat R, Bukhari MH, Saeed S, Hamid T. Comparison of fine needle aspiration cytology and thyroid scan in solitary thyroid nodule. Patholog Res Int. 2011;2011:754041. Crossref

11. Bagga PK, Mahajan NC. Fine needle aspiration cytology of thyroid swellings: how useful is it? Indian J Cancer.2010; 47:437-42. $\underline{\text { Crossref }}$

12. Morgan JL, Serpell JW, Cheng MS. Fine needle aspiration cytology of thyroid nodules: how useful is it? Anz J Surg. 2003;73:480-3. $\underline{\text { Crossref }}$

13. Mahar SA, Husain A, Islam N. Fine needle aspiration cytology of thyroid nodule: diagnostic accuracy and pitfalls. J Ayub Med Coll Abbottabad. 2006;18:26-9. Crossref
14. Chandanwale S, Singh N, Kumar H, Pradhan P, Gore C, Rajpal M. Clinicopatholological correlation of thyroid nodules. Int J Pharm Biomed Sci 2012;3:97-102.

15. Meraj FA, Fatemeh SR, Perviz FA. Determining sonographic and needle aspiration(FNAC) accuracy in thyroid nodules diagnosis in patients. Bull. Env. Pharmacol. Life Sci.2013;2:45- 50.

16. Prakash HM, Jyothi BL, Hiremath SS, Kishanprasad H L, Nagesh TS, Joshua DJM. Panorama of solitary thyroid nodule. Int J Med Health Sci.2012;1:19-26.

17. Gupta M, Gupta S, Gupta BV. Correlation of fine needle aspiration cytology with histopathology in the diagnosis of Solitary thyroid nodule. J Thyroid Res. 2010;2010:379051. Crossref 